
\title{
25 Research Soure \\ Predictive Value of NLR and Bilirubin Levels in the Readmission of AECOPD
}

\section{Lu Dai}

Sichuan University West China Hospital

Binmiao Liang ( $\sim$ liangbinmiao@163.com )

Xuemei Ou

Sichuan University West China Hospital

\section{Research article}

Keywords: Acute exacerbation of chronic obstructive pulmonary disease, readmission, NLR, bilirubin

Posted Date: July 13th, 2020

DOI: https://doi.org/10.21203/rs.3.rs-41059/v1

License: (9) This work is licensed under a Creative Commons Attribution 4.0 International License. Read Full License 


\section{Abstract}

Objective To analyze acute exacerbation of chronic obstructive pulmonary disease(AECOPD) readmission events and to determine whether neutrophil-to-lymphocyte ratio(NLR) and bilirubin level are associated with readmission after discharge due to AECOPD .

Methods A total of 170 patients with AECOPD were included. Patients were stratified into the readmission group if patients have two or more readmission within 2 years of the previous discharge and nonreadmission group with one readmission or none within 2 years of the last discharge. Basic characteristics, laboratory examinations and clinical data of them were collected retrospectively and compared between these two groups. Then the patients were separated by the cutoffs of NLR and bilirubin level. The number of all-cause readmission within 2 years, time to first COPD-related readmission, 1-year and 2-year COPD-related readmission, 1-year and 2-year all-cause mortality were compared between groups respectively .

Results Compared with readmission group, patients of non-readmission group had shorter length of hospital stay $(P=0.034)$, more systemic corticosteroids use $(P=0.007)$, higher $N L R(P=0.001)$, higher bilirubin levels $(P=0.010)$ and lower eosinophils counts $(P=0.001)$. NLR and bilirubin level at admission can significantly influence the number of all-cause readmission $(p=0.002, P<0.001$, respectively). Lower bilirubin was associated with an increased risk of 1-year COPD-related readmission(OR $5.063,95 \% \mathrm{Cl}$ 1.091-23.498) and 2-year COPD-related readmission(OR 4.699, 95\% Cl 1.269-17.396) .

Conclusion For patients with AECOPD, longer hospital stay and less use of systemic corticosteroids may be associated with higher risk of readmission. NLR and bilirubin level at admission may be related to the number of all-cause readmission. Bilirubin can be regarded as a biomarker to predict readmission rates within 2 years after discharged throughout the course of disease.

\section{Background}

Chronic obstructive pulmonary disease(COPD) is a preventable and treatable disease with characteristics of persistent respiratory symptoms and airflow limitation[1]. Because of the ageing population, tobacco exposure and heavy air pollution, the burden of COPD keep growing in China, with high prevalence in Chinese adults[2, 3]. According to the Global Burden of Disease Study 2010, COPD were on the top three leading causes of death in China in 2010[4]. The same finding was presented in 2013[5]. Acute exacerbation of chronic obstructive pulmonary disease(AECOPD) means the aggravation of a COPD patient's condition exceeds the range of daily stability and needs further treatments[6], which is common in most of COPD patients. This kind of exacerbation may change the course of prognosis, bring about significant morbidity and mortality, and increase economic and health burden.

Since AECOPD usually require hospitalizations, finding proper predictors or risk factors to improve the prognosis of COPD patients and decrease the risk of their readmission may be impending. Exacerbation could be prevented if we find out such factors that enable patients to get timely and appropriate 
treatments when aggravating[7]. Studies have showed that some of the blood biomarkers such as inflammatory medium and chemotactic factors may have diagnostic and prognostic value of COPD and its exacerbation[8]. Recently, researchers have found that neutrophil-to-lymphocyte ratio(NLR) can not only predict COPD progression and outcomes, but also an independent predictor of COPD mortality[912]. Bilirubin is also confirmed to be a protective index that associated with a lower rate of COPD progression and risk of exacerbation[13]. But up till now, few studies have explored the predictive value of NLR and bilirubin levels in the readmission of AECOPD. The objective of this study is to analyze AECOPD readmission events and to determine whether NLR and bilirubin are associated with readmission after discharge due to AECOPD.

\section{Methods}

Patients hospitalized for AECOPD at West China Hospital, Sichuan University, chengdu, China, between January 2013 and March 2018 were collected. After excluding those who were absence of clinical databases, we included 58 patients with two or more readmission within 2 years of the previous discharge(readmission group) and randomly selected 112 patients with one readmission or none within 2 years of the last discharge(non-readmission group).

Once the two groups of patients were settled, basic characteristics, laboratory examinations and clinical data of them were collected retrospectively. Basic characteristics included age, sex, length of hospital stay, smoking status and specific comorbidities during hospitalization. Laboratory examinations included white blood cells(WBC) count, NLR, eosinophil count, bilirubin, cystatin, C-reactive protein(CRP), Interleukin 6(IL-6), procalcitonin(PCT), arterial blood gas analysis(including P02, PCO2)and ejection fraction(EF) from echocardiography at admission, multiple resistant bacterial and fungal infections during hospitalization according to sputum culture were also collected. Clinical data included the use of mechanical ventilation, systemic corticosteroids, antibiotics and mortality. After discharged, we recorded the number of all-cause readmission within 2 years, time to first COPD-related readmission, 1-year and 2year COPD-related readmission(yes/no), 1-year and 2-year all-cause mortality(yes/no) .

The variables were compared between readmission group and non-readmission group. Data are presented as mean \pm SD for quantitative variables or as number and percentage for categorical variables. The Student's $t$-test or the Wilcoxon rank test were used for quantitative variables while the Chi-square test were used for categorical variables. We performed receiver operating characteristic (ROC) curve on NLR and bilirubin level and obtained the cutoffs of these two variables. A p-value of $\leq 0.05$ was considered as a significant difference.

\section{Results}

There are total 170 patients in our study, consisting of 117 men and 52 women. The mean age of these patients was $72.39 \pm 9.67$ years. $57.65 \%$ percent of them were smokers and the mean tobacco consumption was $21.97 \pm 27.15$ per year. The length of hospital stay of non-readmission group was 
about one day shorter than readmission group( $15.12 \pm 10.21 d$ vs $16.05 \pm 6.36 d, p=0.034)$. There were no significant differences when concerning comorbidities between two groups. Whether the patients were infected by multiple resistant bacteria or fungus showed no significance either.(Table 1)

Table 1

Patients' characteristics and comorbidities

\begin{tabular}{|lllll|}
\hline & $\begin{array}{l}\text { Total } \\
(\mathbf{n = 1 7 0 )}\end{array}$ & $\begin{array}{l}\text { Non- } \\
\text { readmission } \\
\text { group(n=112) }\end{array}$ & $\begin{array}{l}\text { Readmission } \\
\text { group(n= }\end{array}$ & $\begin{array}{l}\text { P } \\
\text { value }\end{array}$ \\
\hline Age (years) & $72.39 \pm 9.67$ & $73.58 \pm 9.44$ & $70.10 \pm 9.75$ & 0.025 \\
\hline Sex (n, \%) & & & & \\
\hline Men & $117(68.82 \%)$ & $75(66.96 \%)$ & $42(72.41 \%)$ & \\
\hline Women & $53(31.18 \%)$ & $37(33.04 \%)$ & $16(27.59 \%)$ & \\
\hline Length of hospital stay(days) & $15.44 \pm 9.07$ & $15.12 \pm 10.21$ & $16.05 \pm 6.36$ & 0.034 \\
\hline Smoking status(n, \%) & $98(57.65 \%)$ & $64(57.14 \%)$ & $34(58.62 \%)$ & 0.853 \\
\hline Tobacco consumption & $21.97 \pm$ & $21.19 \pm 28.60$ & $23.53 \pm$ & 0.357 \\
\hline per year) & 27.15 & & 24.18 & \\
\hline $\begin{array}{l}\text { Multiple resistant bacterial infection(n, } \\
\%)\end{array}$ & $44(25.88 \%)$ & $29(25.89 \%)$ & $15(25.86 \%)$ & 0.997 \\
\hline Fungal infection(n, \%) & $79(46.47 \%)$ & $56(50.00 \%)$ & $23(39.66 \%)$ & 0.200 \\
\hline Comorbidities(n, \%) & $166(97.65 \%)$ & $108(96.43 \%)$ & $58(100.00 \%)$ & 0.185 \\
\hline Coronary heart disease & $20(11.76 \%)$ & $12(10.71 \%)$ & $8(13.79 \%)$ & 0.555 \\
\hline Atherosclerosis & $7(4.12 \%)$ & $3(2.68 \%)$ & $4(6.90 \%)$ & 0.181 \\
\hline Lung cancer & $27(15.88 \%)$ & $15(13.39 \%)$ & $12(20.69 \%)$ & 0.217 \\
\hline Pulmonary heart disease & $73(42.94 \%)$ & $47(41.96 \%)$ & $26(43.10 \%)$ & 0.721 \\
\hline Bronchiectasis & $30(17.65 \%)$ & $19(16.96 \%)$ & $11(18.97 \%)$ & 0.688 \\
\hline Data are presented as mean \pm SD or numbers(\%), as appropriate. & & \\
\hline & & & & \\
\hline
\end{tabular}

Laboratory examinations between non-readmission group and readmission group showed some differences. The non-readmission group had a significantly higher NLR $(14.42 \pm 31.17$ vs $7.17 \pm 8.95, p=$ $0.001)$ and bilirubin $(12.20 \pm 6.04 \mu \mathrm{mol} / \mathrm{L}$ vs $10.46 \pm 7.58 \mu \mathrm{mol} / \mathrm{L}, \mathrm{p}=0.010)$ than readmission group, while the readmission group had a significantly higher eosinophil counts $\left(0.24 \pm 0.5910^{\wedge} 9 / \mathrm{L}\right.$ vs $0.12 \pm$ $0.1910^{\wedge} 9 / \mathrm{L}, \mathrm{p}=0.001$ ) compared with non-readmission group.( Table 2 ) 
Table 2

Patients' laboratory examinations

\begin{tabular}{|lllll|}
\hline & $\begin{array}{l}\text { Total } \\
(\mathbf{n}=\mathbf{1 7 0})\end{array}$ & $\begin{array}{l}\text { Non-readmission } \\
\text { group(n=112) }\end{array}$ & $\begin{array}{l}\text { Readmission } \\
\text { group(n= 58) }\end{array}$ & P value \\
\hline WBC count(10^9/L) & $8.83 \pm 4.76$ & $9.17 \pm 4.89$ & $8.17 \pm 4.46$ & 0.116 \\
\hline NLR & $11.93 \pm 25.99$ & $14.42 \pm 31.17$ & $7.17 \pm 8.95$ & 0.001 \\
\hline Eosinophil counts $\left(10^{\wedge} 9 / \mathrm{L}\right)$ & $0.14 \pm 0.38$ & $0.12 \pm 0.19$ & $0.24 \pm 0.59$ & 0.001 \\
\hline Bilirubin( $\mu \mathrm{mol} / \mathrm{L})$ & $11.60 \pm 6.64$ & $12.20 \pm 6.04$ & $10.46 \pm 7.58$ & 0.010 \\
\hline Cystatin(mg/L) & $1.18 \pm 0.59$ & $1.22 \pm 0.61$ & $1.10 \pm 0.55$ & 0.070 \\
\hline CRP(mg/L) & $41.27 \pm 52.90$ & $42.60 \pm 54.23$ & $39.07 \pm 50.10$ & 0.179 \\
\hline IL-6(pg/ml) & $52.89 \pm 103.70$ & $66.37 \pm 121.25$ & $23.24 \pm 32.31$ & 0.052 \\
\hline PCT(ng/ml) & $0.54 \pm 2.08$ & $0.65 \pm 2.43$ & $0.28 \pm 0.77$ & 0.908 \\
\hline PO2(mmHg) & $90.43 \pm 48.05$ & $92.36 \pm 54.66$ & $85.21 \pm 21.88$ & 0.923 \\
\hline PCO2(mmHg) & $53.86 \pm 62.94$ & $47.54 \pm 13.90$ & $70.33 \pm 117.33$ & 0.400 \\
\hline EF(\%) & $65.09 \pm 9.35$ & $65.5 \pm 9.94$ & $64.20 \pm 8.00$ & 0.165 \\
\hline Data are presented as mean \pm SD. & & & \\
\hline
\end{tabular}

In relation to clinical treatments and mortality, the only difference was the use of systemic corticosteroids $(p=0.007)$, showed more frequent in non-readmission group $(50.89 \%$ vs $29.31 \%)$. The mortality of these two groups represented no difference.(Table 3 )

Table 3

Patients' clinical treatments and mortality

\begin{tabular}{|lllll|}
\hline & $\begin{array}{l}\text { Total } \\
(\mathbf{n = 1 7 0 )}\end{array}$ & $\begin{array}{l}\text { Non-readmission } \\
\text { group(n=112) }\end{array}$ & $\begin{array}{l}\text { Readmission } \\
\text { group( } \mathbf{n = 5 8 )}\end{array}$ & P value \\
\hline Use of mechanical ventilation(n, \%) & $44(25.88 \%)$ & $32(28.57 \%)$ & $12(20.69 \%)$ & 0.266 \\
\hline Use of systemic corticosteroids(n, \%) & $74(43.53 \%)$ & $57(50.89 \%)$ & $17(29.31 \%)$ & 0.007 \\
\hline Use of antibiotics(n, \%) & $153(90.00 \%)$ & $103(91.96 \%)$ & $50(86.21 \%)$ & 0.235 \\
\hline Mortality $(\mathrm{n}, \%)$ & $25(14.71 \%)$ & $18(16.10 \%)$ & $7(12.10)$ & 0.540 \\
\hline Data are presented as numbers $(\%)$. & & & & \\
\hline
\end{tabular}

As showed in Table 2, NLR, eosinophil counts and bilirubin level were significantly different between readmission group and non-readmission group $(p=0.001, p=0.001, p=0.010$, respectively). Previous studies have demonstrated that eosinophil counts $\geq 2 \%$ of WBC count may be a predictor of AECOPD 
risks[14]. Refer to this, we performed ROC curve on NLR and bilirubin to obtain the cutoffs of these two variables.

The ROC curve on NLR showed the cutoffs was 4.87(Area Under the Curve (AUC)was $0.651,95 \% \mathrm{Cl} 0.562-$ 0.741 \sensitivity $=0.667 \square$ specificity $=0.621)$ (Fig. 1$)$. We divided the patients into two groups on the basis of this cutoff value : low NLR group(NLR $<4.87, n=74)$ and high NLR group(NLR $\geq 4.87, n=96)$. There is significantly difference between two groups with regards to the number of all-cause readmission $(p=$ 0.002). The 1-year and 2-year COPD-related readmission and all-cause mortality showed few differences. (Table 4)

Table 4

Association between NLR and readmission events

\begin{tabular}{|c|c|c|c|c|}
\hline & $\begin{array}{l}\text { low NLR } \\
\text { group }(n=74)\end{array}$ & $\begin{array}{l}\text { high NLR } \\
\text { group(n=96) }\end{array}$ & $\mathrm{OR}(95 \% \mathrm{Cl})$ & $P$ value \\
\hline Length of hospital stay(days) & $14.03 \pm 6.88$ & $16.39 \pm 10.37$ & & 0.101 \\
\hline $\begin{array}{l}\text { number of all-cause } \\
\text { readmission within } 2 \\
\text { years(n) }\end{array}$ & $1.91 \pm 2.12$ & $1.10 \pm 1.76$ & & 0.002 \\
\hline $\begin{array}{l}\text { time to first COPD-related } \\
\text { readmission(days) }\end{array}$ & $\begin{array}{l}288.03 \pm \\
235.43\end{array}$ & $\begin{array}{l}218.81 \pm \\
205.63\end{array}$ & & 0.223 \\
\hline $\begin{array}{l}\text { 1- year COPD-related } \\
\text { readmission(n,\%) }\end{array}$ & $22(29.73 \%)$ & $33(34.38 \%)$ & $\begin{array}{l}1.238(0.645- \\
2.378)\end{array}$ & 0.521 \\
\hline $\begin{array}{l}\text { 2- Year COPD-related } \\
\text { readmission(n,\%) }\end{array}$ & $31(41.89 \%)$ & $38(39.58 \%)$ & $\begin{array}{l}0.909(0.490- \\
1.684)\end{array}$ & 0.761 \\
\hline 1-year all-cause morality $(n, \%)$ & $7(9.46 \%)$ & $17(17.71 \%)$ & $\begin{array}{l}2.055(0.803- \\
5.257)\end{array}$ & 0.127 \\
\hline $\begin{array}{l}\text { 2-year all-cause } \\
\text { mortality }(n, \%)\end{array}$ & $7(9.46 \%)$ & $18(18.75 \%)$ & $\begin{array}{l}2.204(0.867- \\
5.602)\end{array}$ & 0.091 \\
\hline
\end{tabular}

In order to wipe off the errors on bilirubin level effected by liver disease and blood system disease, we deleted data from patients under these conditions. The ROC curve on bilirubin showed the cutoffs was $13.55 \mu \mathrm{mol} / \mathrm{L}$ (AUC was $0.620,95 \% \mathrm{Cl} 0.534-0.707$, sensitivity $=0.333 \square$ specificity $=0.897$ )(Fig. 2 ). According to the cutoff value we also divided the patients into two groups: low bilirubin group(bilirubin < $13.55 \mu \mathrm{mol} / \mathrm{L}, \mathrm{n}=75$ ) and high bilirubin group(bilirubin $\geq 13.55 \mu \mathrm{mol} / \mathrm{L}, \mathrm{n}=20$ ). Patients of the low bilirubin group had a mean of 1.96 readmission within 2 years after discharge, 27 of the patients(36.00\%) get readmitted to hospital within the following 1 years and 34 of the patients(45.33\%) get readmitted 
withing the following 2 year of the last hospital discharge because of AECOPD. The results showed above were significantly higher than high bilirubin group. Patients with lower bilirubin level had a 5 -fold greater risk of 1-year COPD-related readmission(OR 5.063, 95\% Cl 1.091-23.498), and 4-fold greater risk of occurring COPD-related readmission within 2 years after discharge(OR 4.699, 95\% $\mathrm{Cl} 1.269-17.396$ ) compare to those who had a higher bilirubin. The 1-year and 2-year all-cause mortality between the two groups showed no differences.(Table 5)

Table 5

Association between bilirubin and readmission events

\begin{tabular}{|c|c|c|c|c|}
\hline & $\begin{array}{l}\text { Low bilirubin } \\
\text { group(n = } \\
75)\end{array}$ & $\begin{array}{l}\text { High } \\
\text { bilirubin } \\
\text { group( } \mathrm{n}= \\
20)\end{array}$ & $\mathrm{OR}(95 \% \mathrm{Cl})$ & $\begin{array}{l}P \\
\text { value }\end{array}$ \\
\hline Length of hospital stay(days) & $14.96 \pm 7.80$ & $11.65 \pm 5.63$ & & 0.054 \\
\hline $\begin{array}{l}\text { number of all-cause } \\
\text { readmission within } 2 \text { years }(n)\end{array}$ & $1.96 \pm 2.29$ & $0.25 \pm 0.55$ & & $<0.001$ \\
\hline $\begin{array}{l}\text { time to first COPD-related } \\
\text { readmission(days) }\end{array}$ & $\begin{array}{l}232.24 \pm \\
228.12\end{array}$ & $\begin{array}{l}250.67 \pm \\
200.29\end{array}$ & & 0.999 \\
\hline $\begin{array}{l}\text { 1- year COPD-related } \\
\text { readmission(n,\%) }\end{array}$ & $27(36.00 \%)$ & $2(10.00 \%)$ & $\begin{array}{l}5.063(1.091- \\
23.498)\end{array}$ & 0.025 \\
\hline $\begin{array}{l}\text { 2-year COPD-related } \\
\text { readmission(n,\%) }\end{array}$ & $34(45.33 \%)$ & $3(15.00 \%)$ & $\begin{array}{l}4.699(1.269- \\
17.396)\end{array}$ & 0.013 \\
\hline 1-year all-cause morality(n,\%) & $7(9.33 \%)$ & $4(20.00 \%)$ & $\begin{array}{l}2.357(0.614- \\
9.042)\end{array}$ & 0.184 \\
\hline 2-year all-cause mortality(n,\%) & $8(10.67 \%)$ & $4(20.00 \%)$ & $\begin{array}{l}2.031(0.543- \\
7.596)\end{array}$ & 0.236 \\
\hline
\end{tabular}

\section{Discussion}

In our study, we observed that patients with COPD who had 1 time or none readmission during the following 2 years after discharged, compared with those who had 2 times or more readmission during that period, had shorter length of hospital stay, more systemic corticosteroids use, higher NLR, higher bilirubin levels and lower eosinophils counts.

In this study, patients of non-readmission group had higher rate of using systemic corticosteroids and lower length of hospital stay. Systemic corticosteroids were recommended to AECOPD patients according to The Global Initiative for Chronic Obstructive Lung Disease (GOLD) guidelines[1]. Systemic 
corticosteroids may improve the prognosis of these patients, hence decrease their risks of readmission. Several studies have shown that the use of systemic corticosteroid therapy can improve airflow limitations and lung function, reduce the likelihood of treatment failure, decrease the risk of relapse, and decrease the length of hospital stay[15-18], which is in accordance to the results above.

We also find that patients with more readmission times had higher eosinophil counts in comparison to non-readmission group. Prins et al found that patients with blood eosinophils $\geq 2 \%$ at admission had a higher risk of relapse, which associated with higher readmission rates in AECOPD[19]. This may partly explained by the previous findings that eosinophilic patients were less likely to be treated by antibiotics[14]or the fact that these patients with higher eosinophils were less treated by systemic corticosteroids in our study. Previously study have also demonstrated that AECOPD patients who have increased blood eosinophil count at admission have higher risk of readmission, which emphasized that eosinophil counts can be regarded as a biomarker to predict COPD hospital readmission[20-22].

In our sample, referring to the cutoff point of eosinophil levels, we find out the cutoffs of NLR that have the best sensitivity and specificity. The comparison between two groups divided from NLR $\geq 4.87$ shows significantly difference in number of all-cause readmission within 2 years. One of the important pathological mechanisms of COPD is inflammation reaction. The level of some inflammatory indices are directly proportional to the severity of COPD. In recent years NLR was regarded as a new inflammatory index which can assess the severity of COPD[23]. Researchers have found that NLR has inverse relationship with airflow limitation[24] and associated with the severity and exacerbation of COPD[25]. It can not only predict COPD progression and outcomes, but also an independent predictor of COPD mortality[9-12]. In the other hand, Emine Aksoy et al[26] showed NLR levels were higher in patients with lower eosinophil counts, who also had higher mortality and higher use of corticosteroids. COPD patients who has higher counts of eosinophil and use less corticosteroids may face a higher risk of readmission. Other studies have also demonstrated, as in our study, an increased risk of COPD readmission in the following one years after discharged in those who had a higher eosinophil counts with lower NLR levels[27]. Thus, our findings that NLR level has a negative relationship with eosinophil counts and readmission rates does not contradict with previous studies. NLR level seems available to be regarded as a predictor of the numbers of AECOPD readmission events. Whether it is related to AECOPD readmission rates needs further study.

We also reported the cutoffs of bilirubin, $13.55 \mu \mathrm{mol} / \mathrm{L}$, in this study and split up the patients into low bilirubin group and high bilirubin group. It also presents significantly difference in number of all-cause readmissions within 2 years, and 1-year/2-year COPD-related readmission. Bilirubin is the end product of Heme oxygenase (HO)-bilirubin system, which is a crucial anti-oxidant path in human body[28]. Some authors have observed that bilirubin present great anti-oxidant properties, preventing the oxidative damage caused by oxidant-related stimulation. Patients who had a higher level of bilirubin may had a lower response of oxidative stress in their body. Several studies have found that high bilirubin level is significantly associated with higher forced expiratory volume in $1 \mathrm{~s}$ to forced vital capacity(FEV1/FVC) and mean forced expiratory flow between 25 and 75\% of FVC (FEF25-75\%) [29-30]. It suggests that 
bilirubin may has a protective effect on lung tissue by impressing the inflammation and oxidative stress response in lungs[31], and was associated with a lower risk of respiratory disease and all-cause mortality[32]. Kirstin E Brown et al[13]also showed, as in our study, that elevated serum bilirubin level are associated with a lower risk of AECOPD, hence it can be used as a biomarker of AECOPD risk.

This study does have some limitations. First, since this is a retrospective study within 2 years, there must be size effect and usual bias which cannot be neglected. Studies with larger amounts of databases are needed to further confirm these findings. Second, since all of the information were collected through electronic medical records only in our hospital, the missing of readmission information of those patients who seek medical assistance in local hospital seems inevitable. This could have influenced the results obtained in this study.

\section{Conclusions}

Among patients hospitalized for AECOPD with longer hospital stay and less use of systemic corticosteroids may be associated with higher risk of readmission. NLR and bilirubin level at admission may be related to the number of all-cause readmissions. Bilirubin can be regarded as a biomarker to predict readmission rates within 2 years after discharged throughout the course of disease.

\section{Abbreviations}

\section{AECOPD}

Acute exacerbation of chronic obstructive pulmonary disease

AUC

Area Under the Curve

COPD

Chronic obstructive pulmonary disease

CRP

C-reactive protein

$\mathrm{EF}$

ejection fraction

IL-6

Interleukin 6

NLR

Neutrophil-to-lymphocyte ratio

PCT

Procalcitonin

ROC

Receiver operating characteristic

WBC

White blood cells 


\section{Declarations}

\section{Ethics approval and consent to participant}

Our study was approved by the Institutional Ethical Committee for Clinical and Biomedical Research of the Sichuan University, West China Hospital. And informed consent was waived because this was a retrospective study.

\section{Consent for publication}

Not applicable

\section{Availability of data and materials}

The datasets analysed during the current study are available from the corresponding author upon reasonable request.

\section{Competing interests}

None of all authors have any financial or non-financial competing interests in this manuscript.

\section{Funding}

This study was partly supported by the National Key Research and Development Program of China (2016YFC1304303) and the Sichuan Science and Technology Agency Grant (2018SZ0109 and 2019YFS0033).

\section{Authors' contributions}

LD, BMO and XMO had full access to all of the data in the study and take responsibility for the integrity of the data and the accuracy of the data analysis. LD contributed substantially to the study design, data collection, analysis and interpretation, and writing of the manuscript. BML and XMO contributed substantially to the study design, analysis, and review of the manuscript. The authors read and approved the final manuscript.

\section{Acknowledgements}

Not applicable

\section{References}

1. Global Initiative for Chronic Obstructive Lung Disease. Global strategy for the diagnosis, management and prevention of chronic obstructive pulmonary disease 2019 report[EB/OL].[2018-1202]. https://goldcopd.org/gold-reports/ 
2. Wang $C, X u J$, Yang $L$, et al. Prevalence and risk factors of chronic obstructive pulmonary disease in China (the China Pulmonary Health [CPH] study): a national cross-sectional study. 2018;391(10131):1706-1717. doi:10.1016/S0140-6736(18)30841-9

3. Zhu B, Wang Y, Ming J, Chen W, Zhang L. Disease burden of COPD in China: a systematic review. Int J Chron Obstruct Pulmon Dis. 2018;13:1353-1364. Published 2018 Apr 27. doi:10.2147/COPD.S161555

4. Xu G, Zhang Z, Lv Q, et al. NSFC health research funding and burden of disease in China. PLoS One. 2014;9(11):e111458. Published 2014 Nov 4. doi:10.1371/journal.pone.0111458.

5. Zhou M, Wang H, Zhu J, et al. Cause-specific mortality for 240 causes in China during 1990-2013: a systematic subnational analysis for the Global Burden of Disease Study 2013. 2016;387(10015):251-272. doi:10.1016/S0140-6736(15)00551-6

6. Magnoni MS, Rizzi A, Visconti A, Donner CF. AIMAR survey on COPD phenotypes. Multidiscip Respir Med. 2014;9(1):16. Published 2014 Mar 17. doi:10.1186/2049-6958-9-16

7. Burchette JE, Campbell GD, Geraci SA. Preventing Hospitalizations From Acute Exacerbations of Chronic Obstructive Pulmonary Disease. Am J Med Sci. 2017;353(1):31-40. doi:10.1016/j.amjms.2016.06.006

8. Regan EA, Hersh CP, Castaldi PJ, et al. Omics and the Search for Blood Biomarkers in Chronic Obstructive Pulmonary Disease. Insights from COPDGene. Am J Respir Cell Mol Biol. 2019;61(2):143149. doi:10.1165/rcmb.2018-0245PS

9. Paliogiannis $P$, Fois AG, Sotgia $S$, et al. Neutrophil to lymphocyte ratio and clinical outcomes in COPD: recent evidence and future perspectives. Eur Respir Rev. 2018;27(147):170113. Published 2018 Feb 7. doi:10.1183/16000617.0113-2017

10. Liu J, Liu J, Zou Y. Relationship between neutrophil-lymphocyte ratio and short-term prognosis in the chronic obstructive pulmonary patients with acute exacerbation. Biosci Rep. 2019;39(5):BSR20190675. Published 2019 May 14. doi:10.1042/BSR20190675

11. Xiong W, Xu M, Zhao Y, Wu X, Pudasaini B, Liu JM. Can we predict the prognosis of COPD with a routine blood test?. Int J Chron Obstruct Pulmon Dis. 2017;12:615-625. Published 2017 Feb 13. doi:10.2147/COPD.S124041

12. Ye Z, Ai X, Liao Z, You C, Cheng Y. The prognostic values of neutrophil to lymphocyte ratio for outcomes in chronic obstructive pulmonary disease [published correction appears in Medicine (Baltimore). 2019 Aug;98(32):e16859]. Medicine (Baltimore). 2019;98(28):e16371. doi:10.1097/MD.0000000000016371

13. Brown KE, Sin DD, Voelker $\mathrm{H}$, et al. Serum bilirubin and the risk of chronic obstructive pulmonary disease exacerbations. Respir Res. 2017;18(1):179. Published 2017 Oct 24. doi:10.1186/s12931-0170664-0

14. Bafadhel M, McKenna S, Terry S, et al. Acute exacerbations of chronic obstructive pulmonary disease: identification of biologic clusters and their biomarkers. Am J Respir Crit Care Med. 2011;184(6):662-671. doi:10.1164/rccm.201104-05970C 
15. Petite SE, Murphy JA. Systemic Corticosteroid and Antibiotic Use in Hospitalized Patients With Chronic Obstructive Pulmonary Disease Exacerbation. Ann Pharmacother. 2019;53(2):144-150. doi:10.1177/1060028018799696

16. Schweiger TA, Zdanowicz M. Systemic corticosteroids in the treatment of acute exacerbations of chronic obstructive pulmonary disease. Am J Health Syst Pharm. 2010;67(13):1061-1069. doi:10.2146/ajhp090293

17. Walters JA, Tan DJ, White CJ, Gibson PG, Wood-Baker R, Walters EH. Systemic corticosteroids for acute exacerbations of chronic obstructive pulmonary disease. Cochrane Database Syst Rev. 2014; (9):CD001288. Published 2014 Sep 1. doi:10.1002/14651858.CD001288.pub4

18. Leuppi JD, Schuetz P, Bingisser R, et al. Short-term vs conventional glucocorticoid therapy in acute exacerbations of chronic obstructive pulmonary disease: the REDUCE randomized clinical trial. 2013;309(21):2223-2231. doi:10.1001/jama.2013.5023

19. Prins HJ, Duijkers R, Lutter R, et al. Blood eosinophilia as a marker of early and late treatment failure in severe acute exacerbations of COPD. Respir Med. 2017;131:118-124. doi:10.1016/j.rmed.2017.07.064

20. Li Q, Larivée P, Courteau J, et al. Greater eosinophil counts at first COPD hospitalization are associated with more readmissions and fewer deaths. Int J Chron Obstruct Pulmon Dis. 2019;14:331341. Published 2019 Jan 30. doi:10.2147/COPD.S187375

21. Couillard S, Larivée P, Courteau J, Vanasse A. Eosinophils in COPD Exacerbations Are Associated With Increased Readmissions. 2017;151(2):366-373. doi:10.1016/j.chest.2016.10.003

22. Bélanger M, Couillard S, Courteau J, et al. Eosinophil counts in first COPD hospitalizations: a comparison of health service utilization. Int J Chron Obstruct Pulmon Dis. 2018;13:3045-3054. Published 2018 Oct 1. doi:10.2147/COPD.S170743

23. Günay E, Sarınç Ulaşı $\mathrm{S}$, Akar O, et al. Neutrophil-to-lymphocyte ratio in chronic obstructive pulmonary disease: a retrospective study. 2014;37(2):374-380. doi:10.1007/s10753-013-9749-1.

24. Lee H, Um SJ, Kim YS, et al. Association of the Neutrophil-to-Lymphocyte Ratio with Lung Function and Exacerbations in Patients with Chronic Obstructive Pulmonary Disease. PLoS One. 2016;11(6):e0156511. Published 2016 Jun 3. doi:10.1371/journal.pone.0156511

25. Furutate R, Ishii T, Motegi T, et al. The Neutrophil to Lymphocyte Ratio Is Related to Disease Severity and Exacerbation in Patients with Chronic Obstructive Pulmonary Disease. Intern Med. 2016;55(3):223-229. doi:10.2169/internalmedicine.55.5772

26. Aksoy E, Güngör S, Ağca MÇ, et al. A Revised Treatment Approach for Hospitalized Patients with Eosinophilic and Neutrophilic Exacerbations of Chronic Obstructive Pulmonary Disease. Turk Thorac J. 2018;19(4):193-200. Published 2018 Sep 13. doi:10.5152/TurkThoracJ.2018.18004

27. Duman D, Aksoy E, Agca MC, et al. The utility of inflammatory markers to predict readmissions and mortality in COPD cases with or without eosinophilia [published correction appears in Int J Chron Obstruct Pulmon Dis. 2016;11:417]. Int J Chron Obstruct Pulmon Dis. 2015;10:2469-2478. Published 2015 Nov 11. doi:10.2147/COPD.S90330

Page 12/15 
28. Tomaro ML, Batlle AM. Bilirubin: its role in cytoprotection against oxidative stress. Int J Biochem Cell Biol. 2002;34(3):216-220. doi:10.1016/s1357-2725(01)00130-3

29. Leem AY, Kim HY, Kim YS, Park MS, Chang J, Jung JY. Association of serum bilirubin level with lung function decline: a Korean community-based cohort study. Respir Res. 2018;19(1):99. Published 2018 May 23. doi:10.1186/s12931-018-0814-z

30. Curjuric I, Imboden M, Adam M, et al. Serum bilirubin is associated with lung function in a Swiss general population sample. Eur Respir J. 2014;43(5):1278-1288. doi:10.1183/09031936.00055813

31. Dolado I, Swat A, Ajenjo N, De Vita G, Cuadrado A, Nebreda AR. p38alpha MAP kinase as a sensor of reactive oxygen species in tumorigenesis. Cancer Cell. 2007;11(2):191-205. doi:10.1016/j.ccr.2006.12.013

32. Horsfall LJ, Rait G, Walters $\mathrm{K}$, et al. Serum bilirubin and risk of respiratory disease and death. JAMA. 2011;305(7):691-697. doi:10.1001/jama.2011.124

\section{Figures}


ROC Curve

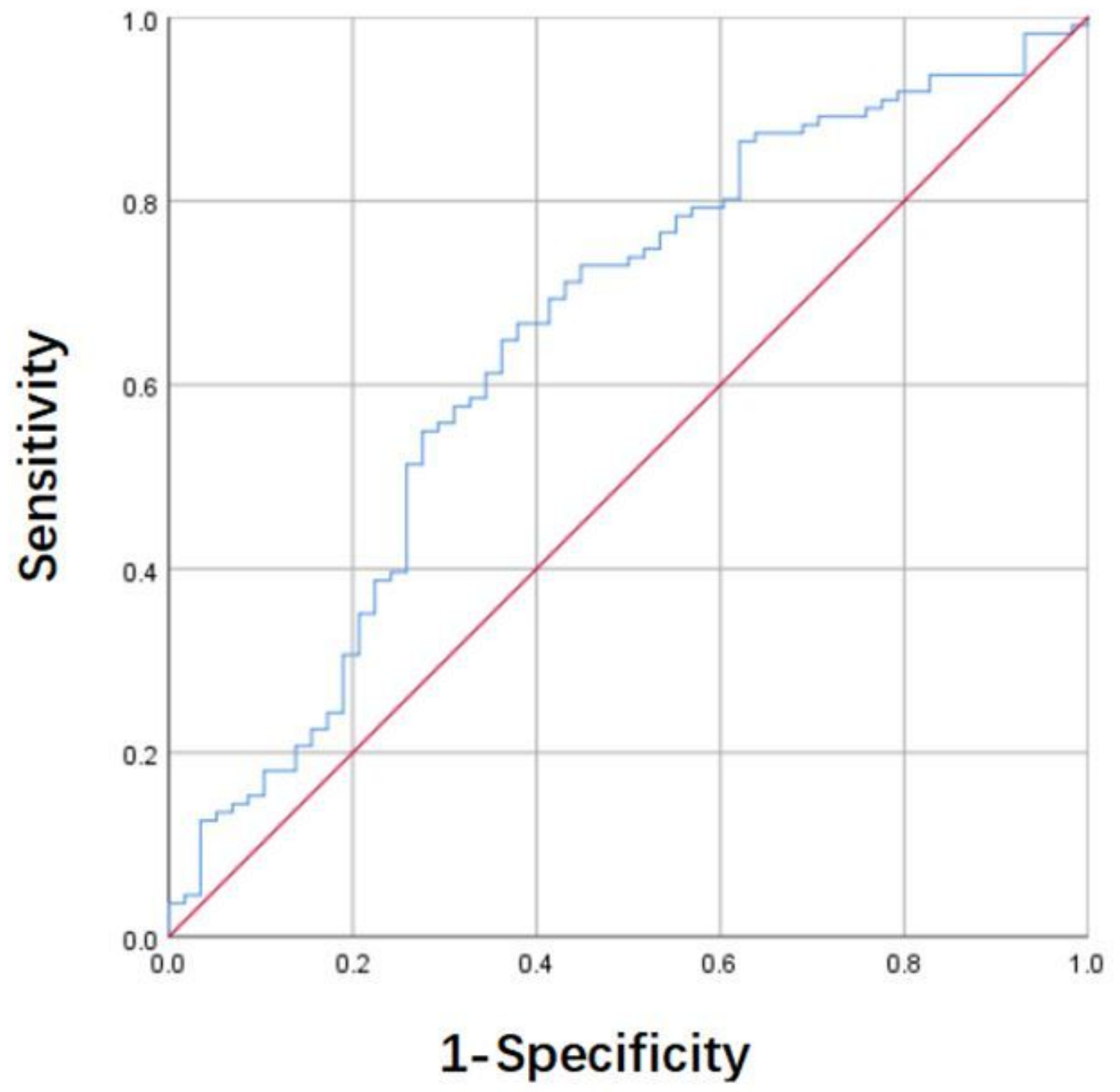

Figure 1

The ROC curve on NLR level. 


\section{ROC Curve}

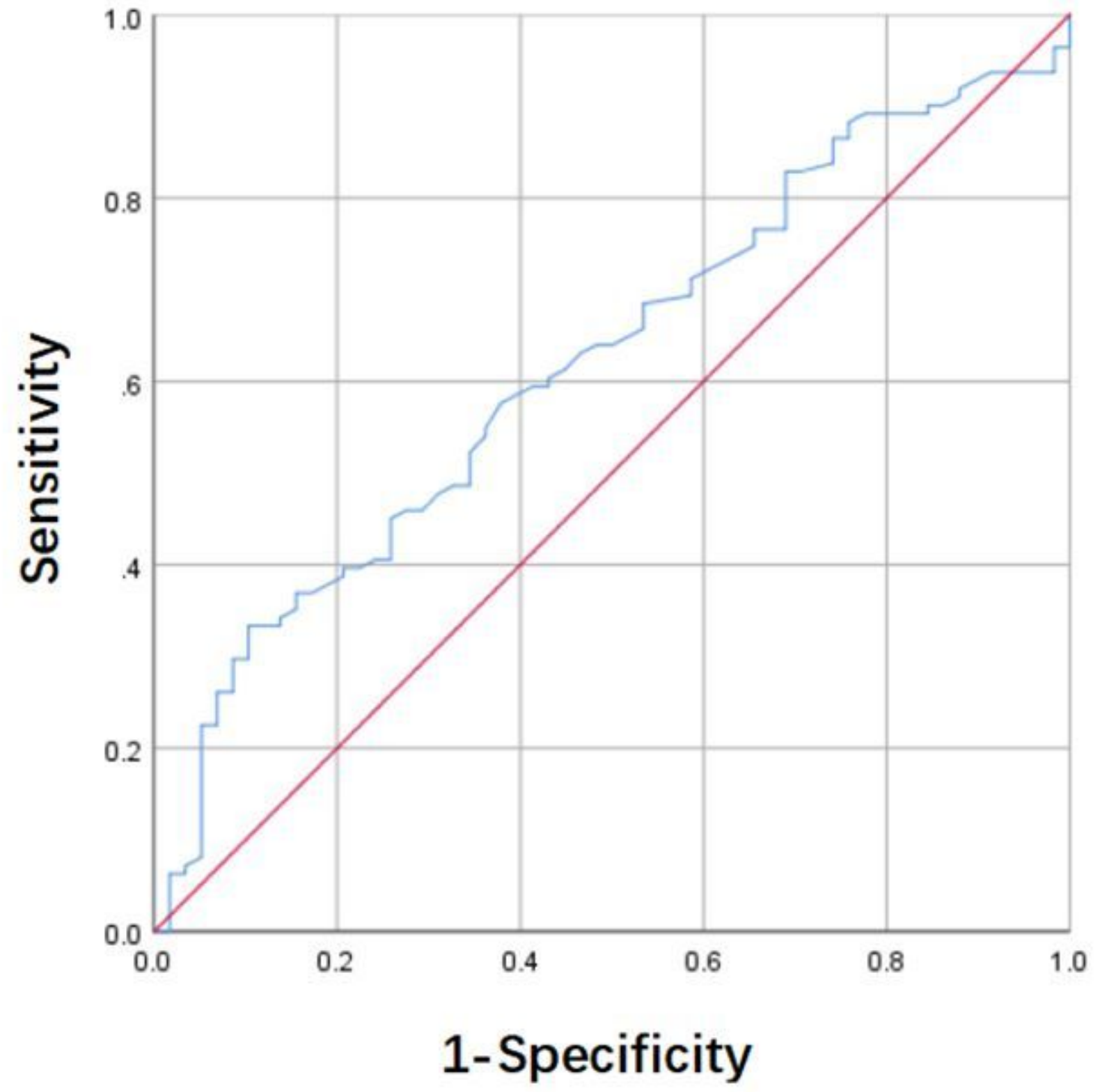

Figure 2

The ROC Curve on bilirubin level 